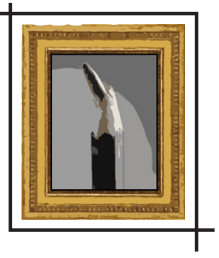

\title{
LIMITES E ENTRECRUZAMENTOS CRÍTICOS ENTRE CIÊNCIA E SOCIEDADE: MAX HORKHEIMER E SEU MATERIALISMO INTERDISCIPLINAR
}

\author{
Eli Borges Júnior*
}

Resumo: No âmbito da proposta de reflexão da revista, oferecemos uma breve, mas muito oportuna, discussão sobre as aporias na relação entre ciência e sociedade a partir de um contexto-chave em que essa reflexão é problematizada: o materialismo interdisciplinar de Max Horkheimer. Procuramos, assim, apresentar algumas de suas principais características e limites, entrevendo possibilidades críticas de produção de conhecimento no interior do sistema de produção capitalista.

Palavras-chave: Ciência e sociedade. Materialismo interdisciplinar. Max Horkheimer. Teoria crítica. Escola de Frankfurt.

Se pudéssemos sobrevoar a trajetória intelectual de Max Horkheimer, verificaríamos possivelmente uma série de momentos ora bastante recortados entre si, ora carentes de uma certa nitidez não só pela forma de escrita um tanto quanto labirintica, mas sobretudo no que diz respeito à apresentação e à defesa de determinados conceitos e teses. Daí a necessidade de se atentar sempre à época de escritura de suas obras e aos conflitos aos quais o próprio autor, propositadamente ou não, impele-nos na leitura e apreciação de seus textos. É diante desse cenário que nos convidamos à tarefa de percorrer algumas dessas obras com o objetivo de realizar uma reflexão sobre a tentativa de Horkheimer de problematizar a ciência de seu tempo, intento que se organizaria fundamentalmente a partir de seu materialismo interdisciplinar.

Para compreender os aspectos fulcrais de tal projeto, realizaremos uma breve investigação sobre o contexto a partir do qual irrompem os elementos que levarão Horkheimer a propor essa nova configuração do processo de conhecimento, bem como suas principais características e arestas limitadoras. Isso se dará, sobretudo, com base em três textos que, embora não contemplados por nós em ordem cronológica (pelos mesmos motivos anterior-

\footnotetext{
* Doutorando e mestre em Ciências da Comunicação pela Universidade de São Paulo (USP). Bacharel em Comunicação Social e em Filosofia pela mesma universidade.E-mail: ridolfi.eli@gmail.com
} 
mente comentados), serão aqui a chave de nossa reflexão: "Teoria tradicional e teoria crítica" (1937), "A presente situação da filosofia social e as tarefas de um instituto de pesquisas sociais" (1931) e "Observações sobre ciência e crise" (1932).

0 projeto do materialismo interdisciplinar nasce, em linhas gerais, de uma profunda insatisfação de Horkheimer no que se refere ao funcionamento da ciência de sua época. Referimo-nos, assim, às primeiras décadas do século XX - sobretudo os anos 1930 -, numa Alemanha que enfrentava, por um lado, as consequências devastadoras da crise de 1929 e, por outro, a crescente ascensão do nazismo e seus efeitos junto ao proletariado. Todo esse conjunto de fatores será determinante na reformulação de uma série de diagnósticos que Marx apresentaria em sua crítica à economia política burguesa.

Nesse sentido, a tarefa de Horkheimer deve ser compreendida dentro da chave que diferencia e estabelece os limites do que ele próprio demarcaria como "teoria tradicional" e "teoria crítica". Isso será exposto no artigo homônimo "Teoria tradicional e teoria crítica", publicado seis anos depois de sua ascensão ao posto de diretor do Instituto de Pesquisa Social de Frankfurt, em janeiro de 1931. Nesse texto, Horkheimer reflete sobre o papel e o funcionamento da ciência na sociedade capitalista, ciência que expressaria, em última medida, além da impossibilidade do conhecer, falaciosas noções de neutralidade e objetividade.

Segundo Horkheimer, há um esforço, por parte das ciências sociais, de incorporar os processos metodológicos característicos das ciências naturais como forma de alcançar resultados dotados de certa margem de certeza ou mesmo de previsibilidade, "a pedra de toque do real para cada ciência"1. A partir de uma série de princípios abstratos, a teoria científica tradicional buscaria formular leis que pudessem de alguma forma expressar fenômenos observados, leis essas cuja perfeição é dada por uma relação entre simplicidade e capacidade de reunir em si mesma um determinado conjunto de princípios.

Tal conceito de teoria, conforme Horkheimer (1973, p. 127), seria transplantado às ciências sociais, as quais se diferenciariam das ciências naturais apenas no que tange às caracteristicas dos objetos examinados: enquanto as "ciências do homem e da sociedade" se dedicariam mais à "pesquisa de fatos", as ciências da natureza privilegiariam os princípios capazes de explicar os fenômenos, uma postura epistemológica que em nada poria em xeque o próprio conceito de teoria ${ }^{2}$. Na teoria tradicional, o cientista tem como tarefa a observação desses fenômenos e da recorrência de determinadas conexões entre eles, tudo de forma objetiva, na medida em que o objeto pesquisado é claramente distinto do sujeito que o pesquisa.

\footnotetext{
1 - Expressão proferida por Horkheimer anos antes, em 1933, por ocasião do XI Congresso Internacional de Sociologia de Genebra, ao se referir à questão da previsibilidade e do grau de falibilidade dos resultados nas ciências humanas. Sua fala transformar-se-ia no artigo "Do problema da previsão nas ciências sociais" (HORKHEIMER, 2012, p. 89).

2 - Sobre isso, ressalvaria especificamente Horkheimer (1973, p. 127): "Não é o significado da teoria em geral que é questionado aqui [em "Teoria tradicional e teoria crítica"], mas a teoria esboçada 'de cima para baixo' por outros, elaborada sem o contato direto com os problemas de uma ciência empirica particular".
} 
A ciência proporciona uma formulação clara, bem visível, de modo que se possam manusear os conhecimentos como se queira. Não importa se se trata de exposição da matéria, como na história e partes descritivas de outras ciências particulares, ou de sinopse de grandes quantidades de dados e obtenção de regras gerais, como na física; para o cientista, a tarefa de registro, modificação da forma e racionalização total do saber a respeito dos fatos é sua espontaneidade, é a sua atividade teórica (HORKHEIMER, 1973, p. 131).

Porém, como se reconfigura a tarefa epistemológica desse modus operandi científico a partir do momento em que as fronteiras entre cientista e objeto não são mais exatamente delimitáveis, como no caso da sociologia? Mais do que isso, seguindo as indagações de Marcos Nobre (2004, p. 36, grifo do autor), em comentário à teoria crítica horkheimeriana, como é possivel estabelecer tal objetividade "quando o objeto em questão (as relações sociais) é um produto da ação humana?".

Chegamos, assim, a uma das mais delicadas arestas do debate sobre o caráter científico das ciências sociais: É possivel separar o papel de cientista daquele de agente social? Para Horkheimer, a incorporação do modelo de funcionamento das ciências naturais às ciências humanas exige, em primeira instância, que haja uma completa cisão entre essas duas figuras sociais; será, pois, a pertinência dessa necessidade, ou a sua viabilidade, um dos pontos nevrálgicos atacados por sua teoria crítica. A confiabilidade do método em ciências sociais só é assim assegurada a partir da afirmação dessa separação, um deslocamento completo entre o "domínio do conhecimento" e o "domínio da ação", nas expressões de Nobre (2004, p. 37, grifo do autor). Como ressalta o filósofo brasileiro, não é admitida ao cientista qualquer valoração do objeto sobre o qual se debruça e, portanto, qualquer tentativa crítica no sentido de questionar a sua própria condição de objeto: deve sim ser classificado e explicado segundo as possibilidades neutras oferecidas pelo método:

$\mathrm{Na}$ concepção tradicional, portanto, a teoria não pode em nenhum caso ter por objetivo a ação, não pode ter um objetivo prático no mundo, mas apenas apresentar a conexão dos fenômenos sociais tais como se apresentam a um observador isolado na prática (NOBRE, 2008a, p. 43).

Mas, além da separação entre conhecimento e ação, outro legado da teoria tradicional sobre as ciências sociais seria o processo de intensa disciplinarização do conhecimento ${ }^{3}$.

3 - A preocupação com o processo de disciplinarização do conhecimento já apareceria nos ensaios anteriores de Horkheimer escritos durante a década de 1930, particularmente em "Observações sobre ciência e crise", de 1932, em que o autor trata do isolamento da ciência, o qual se desdobraria justamente em uma recusa da própria ciência em analisar de forma adequada os problemas relacionados à esfera social. Trataremos disso mais adiante. 
0 modus operandi científico baseado na especialização em ramos restritos de atividades teria sido transplantado para a prática do cientista social, favorecendo a formação de domínios de conhecimento cada vez menos articulados entre si, com conexões cada vez mais frágeis com a totalidade do mundo.

Ao comentar a proposta do materialismo interdisciplinar, Wolfgang Bonß (1993, p. 103-104, tradução nossa) destaca que as ciências especializadas, tal como se organizaram a partir do desenvolvimento das forças burguesas, condicionaram, segundo Horkheimer, a universalização de um "modo de percepção social" no qual a "realidade do mundo dos objetos sociais" está ancorada nos critérios de utilização, exploração e administração, valores diretamente relacionados ao sistema de produção capitalista e que acabam por expressar um modelo de pesquisa um tanto ambíguo:

Por um lado, estruturas reificadas, independentes do sujeito, podem ser articuladas em grande detalhe; por outro lado, a ficção de uma análise "sem pressuposição" da realidade social leva a uma reprodução acrítica dos princípios dominantes de utilização, exploração e administração. 0 mesmo impulso que inicia o progresso nas ciências especializadas, portanto, torna-as limitadas e cegas para suas próprias restrições sociais. ${ }^{4}$

A separação entre conhecimento e ação, entre o estudo dos fatos sociais e a experiência, e o isolamento da ciência no restrito âmbito das disciplinas acabariam por estabelecer uma ciência que, em última medida, estaria a serviço da própria manutenção das condições de funcionamento do sistema capitalista. É diante disso, pois, que Horkheimer elabora sua proposta de reformulação da prática epistemológica nas ciências sociais a partir de seu materialismo interdisciplinar.

É necessário, pois, romper com a lógica da teoria tradicional e empreender uma postura crítica no fazer científico, assumindo as aporias implicadas tanto por um quanto pelo outro modo de trabalho. A teoria tradicional, no afã de se restringir a uma explicação pura e pretensamente "neutra", acabaria por resultar em seu completo contrário: uma versão parcial de conhecimento na medida em que concorre para a manutenção das condições históricas presentes ao se eximir da tarefa de questionamento da própria realidade.

A partir daí, Horkheimer apresenta o que seriam os dois fundamentos da teoria crítica, em contraposição à teoria tradicional: o comportamento crítico e a orientação para a emancipação. Poderiamos dizer que, apesar de terem sido teorizados com especificidade somente em

\footnotetext{
4 - "On the one hand, reified structures, independent of the subject, can be articulated in great detail; on the other hand, the fiction of a 'presuppositionless' analysis of social reality leads to an uncritical reproduction of the dominant principles of utilization, exploitation, and administration. The very impulse that initiates progress in the specialized sciences thus makes them narrow-minded and renders them blind to their own social constraints".
} 
1937, esses dois princípios parecem constituir a base da postura epistemológica do projeto interdisciplinar de Horkheimer.

0 comportamento crítico estaria ligado a uma nova forma de conhecimento que não se abstivesse da reflexão sobre a condição histórica inerente a seu próprio processo. Segundo Horkheimer, é preciso reconhecer a ciência tradicional como resultado da conjuntura capitalista em que se insere: à medida que o mercado e a produção de mercadorias tornam-se aspectos nevrálgicos dessa estrutura, essa ciência, constituída em seu bojo, funcionaria de acordo com a mesma lógica, expressando seus próprios valores e condições de sobrevivência. 0 comportamento crítico, por sua vez, permite refletir sobre tais relações reconhecendo a parcialidade com que se configura a ciência tradicional, a serviço da própria condição de dominação do modo de produção capitalista.

\begin{abstract}
Para os sujeitos do comportamento crítico, o caráter discrepante cindido do todo social, em sua figura atual, passa a ser contradição consciente. Ao reconhecer o modo de economia vigente e o todo cultural nele baseado como produto do trabalho humano, e como a organização de que a humanidade foi capaz e que impôs a si mesma na época atual, aqueles sujeitos se identificam, eles mesmos, com esse todo e o compreendem como vontade e razão: ele é o seu próprio mundo (HORKHEIMER, 1973, p. 138).
\end{abstract}

Nesse sentido, pensar sobre uma nova forma de conhecimento científico requer também pensar sobre uma nova relação entre ciência e sociedade, reconhecendo a ciência não como entidade suprassocial, absolutamente descolada da práxis (forma de assegurar a sua própria cientificidade), mas sim concebendo-a como elemento importante e produção dessa práxis, inscrito nas circunstâncias de uma conjuntura histórica capitalista. Parece ser essa espécie de reconciliação entre ciência e sociedade a que Horkheimer se proporá em seu projeto interdisciplinar.

Embora reconheça a falsa neutralidade da teoria tradicional, o comportamento crítico não tem por objetivo negar em absoluto a concepção tradicional de ciência e seus resultados. Horkheimer (1973, p. 132) vê como possibilidade real a eliminação da parcialidade da teoria tradicional a partir da "consciência concreta da sua limitação", o que pode ser empreendido pela própria teoria crítica. Essa "consciência" permitiria à teoria tradicional reconhecer-se como parte integrante de um sistema produtor de mercadorias, atestando seus próprios resultados como constituintes dessa mesma lógica. Reconhecer sua limitação também envolve ter consciência de seu papel dentro da estrutura de dominação capitalista e, mais do que isso, de sua incapacidade, dada justamente pela lógica do sistema, de empreender qualquer mecanismo de superação dessas condições.

Assim, distintamente da teoria tradicional, que apenas se põe a explicar as características da economia capitalista, a teoria crítica tem, segundo Horkheimer, a capacidade de analisar 
o momento histórico presente sob o pano de fundo de uma perspectiva emancipadora. E será justamente por isso que Horkheimer verá na reflexão marxiana o primeiro sintoma dessa nova possibilidade de análise da sociedade, fundamentalmente a partir de sua crítica à economia política, já em período de certa maturidade intelectual. Apoiado em um diagnóstico de sua própria época, Marx não procurava simplesmente explicar os mecanismos pelos quais funcionava o modo de produção capitalista, mas sim situá-lo numa perspectiva histórica, produto das próprias relações materiais e, portanto, capaz de ser superado a partir da via revolucionária.

Seguir a receita marxiana envolve mesmo a reformulação das próprias conclusões de Marx. E será a isso que Horkheimer se proporá quando da tarefa de realizar um diagnóstico de sua época: a teoria crítica deve estar em permanente renovação, sempre adequada às circunstâncias históricas do presente. Não há, pois, princípios preconcebidos, particulares à teoria crítica, os quais devem ser sempre adotados por seus seguidores: há, mais, uma postura epistemológica que parte dessa contínua necessidade de reatualização e de uma conexão direta com a realidade presente ${ }^{5}$ : "0 que distingue a perspectiva crítica é justamente 0 seu ancoramento real na sociedade, um ancoramento intimamente relacionado com a produção de diagnósticos do tempo" (NOBRE, 2008a, p. 18).

A orientação para a emancipação, que, no limite, representa o ponto em torno do qual gira o próprio comportamento crítico, parece expressar também um dos fins fundamentais do projeto interdisciplinar de Horkheimer. Nesse sentido, o filósofo reafirma constantemente em "Teoria tradicional e teoria crítica" (HORKHEIMER, 1973) a necessidade de resgatar o pensamento teórico das influências do fazer científico tradicional, pensamento esse que ficaria refém da lógica da "utilização", "exploração" e "administração"6 do sistema capitalista.

Na medida em que o pensamento teórico não se relaciona com fins muito especiais ligados
a essas lutas [da classe burguesa], sobretudo com a guerra e sua indústria, diminui o inte-
resse por esse pensamento. Não se emprega mais tanta energia em formar e desenvolver a
capacidade de pensar, independente de seu tipo de aplicação (HORKHEIMER, 1973, p. 136).

Como nos lembra Bonß (1993), será, portanto, a problemática decorrente da distinção entre teoria crítica e teoria tradicional a chave em que Horkheimer proporia seu conceito de materialismo interdisciplinar, o qual, além de ultrapassar as concepções mais ortodoxas

5 - Em um artigo que analisa a atualidade de algumas contribuições da teoria crítica, "Teoria crítica hoje", Marcos Nobre (2008b) destaca que a concepção crítica não pretende se colocar como uma explicação mais adequada da realidade presente, de forma a concorrer com outras teorias que também persigam esse objetivo. Mais do que isso, mostra suas próprias limitações a qualquer lógica que busque situá-la como algo estanque, sem a perspectiva do acompanhamento do curso da própria história. Esse comportamento faz parte, assim, do reconhecimento das aporias da própria teoria crítica.

6 - Em referência à citação de Bonß (1993, p. 103-104). 
de materialismo, superava os modelos de análise social interdisciplinar empreendidos desde Max Weber até Ferdinand Tönnies. Seu conceito de pesquisa interdisciplinar teria sido, complementa BonB (1993, p. 114), fundamentado na contraposição a tais paradigmas burgueses; uma teoria social que poderia superar tais paradigmas desde que os circunscrevesse dentro de uma abordagem materialista e histórica.

A primeira importante reflexão sobre o materialismo interdisciplinar seria realizada por Horkheimer na ocasião de sua posse como diretor do Instituto de Pesquisa Social de Frankfurt, em 24 de janeiro de 1931. Intitulada "A presente situação da filosofia social e as tarefas de um instituto de pesquisas sociais" (HORKHEIMER, 1999), sua conferência de posse expõe alguns dos fundamentos em torno dos quais se organiza seu projeto de realização de um diagnóstico do presente por meio de uma nova articulação entre o pensamento teórico e a perspectiva empírica, o que se expressa a partir de uma relação entre filosofia social, pesquisa social e teoria do curso da história?.

A filosofia social envolveria, na visão de Horkheimer (1999, p. 121), um conjunto geral de hipóteses sobre a estrutura e o desenvolvimento da sociedade em sua totalidade, fornecendo assim uma "interpretação filosófica do destino dos homens, enquanto não são meros indivíduos, mas membros de uma comunidade", ocupando-se sobretudo "daqueles fenômenos que somente podem ser entendidos em conexão com a vida social dos homens: no Estado, no Direito, na Economia, na Religião, ou seja, em toda a cultura material e espiritual da humanidade em geral".

Mas o trabalho da filosofia social deveria se organizar a partir de uma articulação direta com disciplinas diversas do conhecimento científico, como a economia, a sociologia, a história, a própria filosofia, a psicologia social, a crítica de arte. E talvez aqui resida um dos movimentos mais interessantes da proposta científica de Horkheimer na medida em que parece ser possivel perceber, nessa aliança, sua tentativa de reunir paradigma materialista e paradigma burguês, no esforço ainda maior de superação de suas próprias aporias.

A grande missão de Horkheimer fundamenta-se, portanto, na organização de um trabalho interdisciplinar que seja capaz de reunir o que cada disciplina conta de mais peculiar e interessante sobre determinados fenômenos e condições do presente, tudo isso à luz das proposições oferecidas pela filosofia social e inscrito dentro do pano de fundo da história.

A noção de pesquisa interdisciplinar é em geral definida como um "grupo de trabalho em andamento" de vários cientistas que surge "com base em questões filosóficas atuais" ("Lage"8 41/BPSS) e, quase automaticamente, transforma as condições de conhecimento.

7 - Consoante esquema representado por BonB (1993, p. 116).

8 - Aqui Bonß (1993) recorre à própria conferência de Horkheimer que acabamos de citar. Abrevia por "Lage" seu título em alemão: "Die gegenwärtige Lage der Sozialphilosophie und die Aufgaben eines Instituts für Sozialforschung". 
Na medida em que os representantes das várias disciplinas se unem em uma equipe orientada por um problema "e fazem em comum... o que os pesquisadores mesmos sempre fizeram" (ibid.), eles transcendem a fragmentação da ciência e contribuem para superar a oposição entre positivismo e metafísica ${ }^{9}$ (BONB, 1993, p. 118, tradução nossa).

Da mesma forma, é também possivel perceber aqui a própria contraposição de Horkheimer aos métodos da ciência tradicional. A ideia de trabalho em equipe se coloca como alternativa à figura do cientista de gabinete, aquele que analisa em laboratório - e, portanto, alheio à dimensão empírica - seu objeto de pesquisa segundo métodos já predeterminados e circunscritos à especificidade de sua disciplina. Para isso, Horkheimer empreenderia métodos já conhecidos por determinados ramos da pesquisa, trabalhando ainda com a possibilidade de descoberta e fundamentação de novos métodos.

A conferência de Horkheimer nos apresenta, assim, não somente os fundamentos a partir dos quais seu intento interdisciplinar organizar-se-á, mas, sobretudo, assinala-nos o ponto de partida de um projeto de pesquisa que se desenvolverá ao longo da década de 1930, cujos resultados - que veremos aqui muito brevemente - acabariam, paradoxalmente, por entrar em conflito com sua proposta inicial. Diante desse ponto de partida, a missão do Instituto de Pesquisa Social de Frankfurt, como afirma Horkheimer (1999, p. 130), correrá dentro dos trilhos da "ditadura do trabalho planejado", sob sua própria supervisão, e deverá ser capaz de relacionar três campos distintos ${ }^{10}$ : "a vida econômica da sociedade", "o desenvolvimento psíquico dos indivíduos" e "as transformações que têm lugar nas esferas culturais em sentido estrito"11. Com isso, completa-se assim seu intento de aliar universal e particular, empírico e teórico, ciência e sociedade na busca incessante pela verdade.

Os fundamentos que dariam sustentação à proposta apresentada por Horkheimer, ou seja, a seu projeto de construção de uma nova proposta epistemológica, ecoariam sobretudo no texto "Observações sobre ciência e crise", publicado já em 1932. Nesse ensaio, Horkheimer desenvolve não só ideias presentes em sua conferência de posse, mas também já anunciaria

\footnotetext{
9 - "The notion of interdisciplinary research is generally defined as an 'ongoing working group' of various scientists that arises 'on the basis of current philosophical issues' ('Lage' 41/BPSS) and almost automatically transforms the conditions of knowledge. Insofar as the representatives of the various disciplines join together in a problem-oriented team 'and do in common... what proper researchers have always done' (ibid.), they transcend the fragmentation of science and contribute to overcoming the opposition between positivism and metaphysics".

10 - Em seu texto de posse, Horkheimer (1999) comenta a tentativa de relacionar essas três problemáticas sobretudo por reflexões empreendidas a partir de interpretações de Spinoza, Hegel e Marx. No entanto, reafirma a sua busca por uma reformulação dessas reflexões, atualizada de acordo com os métodos e os conhecimentos disponíveis de seu tempo, o que figurará com destaque como a grande âncora de seu materialismo interdisciplinar.

11 - Esferas que compreenderiam, segundo Horkheimer (1999, p. 130), não somente "os chamados conteúdos espirituais da ciência, da arte e da religião", mas também "o direito, os costumes, a moda, a opinião pública, o esporte, as formas de divertimento, o estilo de vida, etc.".
} 
uma série de elementos que comporiam "Teoria tradicional e teoria crítica", de cinco anos depois. 0 ensaio apresenta-se, assim, como base teórica fundamental de seu conceito de materialismo interdisciplinar. Antes de nos encaminharmos às considerações finais deste artigo, façamos, pois, uma breve reflexão sobre alguns de seus principais pontos.

Em seu ensaio, Horkheimer faz inicialmente um exame sobre a situação da ciência de sua época: ao mesmo tempo que chama a atenção inicialmente para o caráter social da ciência, vista por ele como "força produtiva" e "meio de produção" no interior da sociedade capitalista, aponta deficiências em seu processo de desenvolvimento. Em certa medida, Horkheimer parece manifestar uma certa crença no campo científico como importante solucionador das necessidades humanas, herança direta do pensamento teórico marxiano. Ressalvaria, no entanto, que as descobertas científicas e toda a pujança por elas gerada concorreriam não para o desenvolvimento e a melhoria das condições de vida dos povos, mas para o seu contrário. Tais aspectos configurar-se-iam como sinais de uma crise econômica geral, na qual, como complementa Horkheimer (2012, p. 8):

A ciência aparece como um dos múltiplos elementos da riqueza social que não cumprem seu destino. Hoje ela ultrapassa de longe o nivel de bens de épocas anteriores. Há sobre a terra mais matérias-primas, mais máquinas, maior força de trabalho adestrada e melhores métodos de produção do que antes, mas não beneficia correspondentemente aos homens. A sociedade, na sua forma hodierna, mostra-se incapaz de fazer uso real das forças que se desenvolveram dentro dela, e da riqueza produzida no seu âmbito.

Horkheimer principia, assim, a formulação de um diagnóstico de sua época a partir da crítica aos procedimentos científicos e aos modos pelos quais esse fazer científico se inscreve na estrutura social. E isso é fundamental para compreendermos a chave na qual opera o projeto do materialismo interdisciplinar. Ao mesmo tempo, a reflexão de Horkheimer sobre ciência e crise aponta para uma característica desvinculação entre teoria e prática, problemática que receberá especial tratamento em "Teoria tradicional e teoria crítica". Em seu texto de 1932, Horkheimer refere-se a um desvio no que tange a uma "preocupação teórica com a sociedade como um todo", um completo desfavorecimento da razão crítica em privilégio de um pensamento utilitarista voltado à lógica da indústria e da vida diária. Os momentos de crise da ciência, aponta o filósofo, em vez de justamente colocarem em xeque esses modelos científicos, atribuiriam ao próprio pensamento teórico a origem primeira dos problemas.

Horkheimer sinaliza para uma transformação nas pretensões da ciência, transformação essa imposta pelas condições de desenvolvimento da sociedade e que se refletirá diretamente nos procedimentos científicos. 0 esforço de elencar fatos e verificar regularidades entre eles, característico de um momento de pretensões emancipatórias da burguesia, será um dos elementos principais a obliterar o próprio processo científico na medida em que se converte 
numa tarefa burocrática de "registro, classificação e generalização de fenômenos", sem se atentar a sua dimensão fundamental. Assim, o princípio iluminista de busca de uma sociedade melhor é cada vez mais substituído, no meio científico, pelo privilégio do presente.

Essa "trivialização de método e de conteúdo", nas palavras de Horkheimer (2012, p. 9), reflete-se mesmo nas formulações categoriais e na divisão das ciências em disciplinas. Tais modos de operacionalização da ciência estariam dentro de toda uma estrutura de dominação dada pelas condições de desenvolvimento capitalistas, daí a impossibilidade de se compreender a crise da ciência a partir de si mesma. A própria ciência é ideológica: expressão das contradições do sistema, ela mascara as razões reais da crise. Para compreender os fundamentos da crise na ciência, é preciso, pois, compreender as razões da crise geral por meio de uma "teoria correta sobre a situação social atual" (HORKHEIMER, 2012, p. 12), expressão máxima de seu materialismo interdisciplinar.

Mas quais seriam os resultados desse projeto de Horkheimer? Embora tal resposta dê conta de tematizar outro artigo, faz-se necessário ao menos apontar alguns de seus aspectos principais. Ao mesmo tempo que a interdisciplinaridade assume papel fundamental na elaboração do diagnóstico do tempo presente, as investigações do Instituto de Pesquisa Social de Frankfurt deparar-se-iam com conclusões que, no mínimo, problematizariam os próprios limites do materialismo interdisciplinar: a orientação para a emancipação, norte de todo o projeto, parece ganhar contornos cada vez mais indiscerníveis em meio às novas condições nas quais o capitalismo de então se estrutura.

As investigações dos anos 1930 não dariam fim à década antes de revelar uma transformação aguda no jogo de forças entre burguesia e proletariado, sobretudo na Alemanha. As pesquisas com a classe operária geraram um diagnóstico bastante distinto daquele apresentado por Marx, apontando não para o colapso das forças produtivas capitalistas, mas sim para uma flexibilização do próprio sistema ${ }^{12}$ : a crescente intervenção do Estado na economia, contrariando a lógica liberal burguesa do capitalismo de Marx; a diferenciação social no interior do proletariado (com a formação de uma classe econômica média) e da burguesia (que deixa os postos de comando para dar lugar a executivos contratados); e a ascensão dos regimes nazista e fascista, pondo em xeque, como assinalado por Marcos Nobre $(2004$, p. 46), "a capacidade de resistência da classe trabalhadora à dominação capitalista".

É certo que o materialismo interdisciplinar será a importante matriz epistemológica para a definição de um diagnóstico do presente; porém, com os ideais de emancipação solapados pelas formas em que se converteu o capitalismo, ou seja, sem um proletariado capaz de se opor e de transformar o próprio sistema, Horkheimer é levado a uma revisão de seu projeto

12 - Sobre o processo de flexibilização do modo de produção capitalista, sobretudo no que tange ao incremento da intervenção do Estado na economia, vale conferir o diagnóstico do frankfurtiano Friedrich Pollock (1982) em seu "Capitalismo de Estado". 
interdisciplinar no final da década de 1930 para, finalmente, em 1944, condená-lo à sua própria aporia ao concluir, em coautoria com Theodor W. Adorno, sua Dialética do esclarecimento. Nessa obra, os autores assinalam que a vitória dos aliados marcaria de vez a impossibilidade da ação transformadora, relegando o exercício crítico ao campo teórico, uma contraposição direta aos ideais de união entre teoria e prática e, em certa medida, de filosofia social e pesquisa social, que dava cores ao materialismo interdisciplinar.

Em comentário ao projeto de Horkheirmer, Bonß (1993) incita-nos, no entanto, a aventar sobre outras razões para seu abandono, as quais estariam além da impossibilidade da emancipação. Segundo Bonß (1993), a proposta interdisciplinar horkheimeriana não contava com uma concepção de trabalho que fosse realmente inovadora ao integrar as disciplinas. Com um entendimento um tanto quanto "ingênuo" sobre o conceito de pesquisa interdisciplinar, Horkheimer não teria fundamentado uma proposta metodológica consistente capaz de romper efetivamente com os procedimentos científicos tradicionais ${ }^{13}$.

Guardadas as devidas considerações sobre eventuais deficiências metodológicas do materialismo interdisciplinar, o intento de Horkheimer parece não perder importância ao nos depararmos com os resultados de suas principais investigações. Restritas ou não a um período muito particular da história, elas não deixam de expressar o resultado de um movimento dialético que esboça seus traços - quase indiscerníveis porque extremamente efêmeros não somente no pensamento teórico dos próprios frankfurtianos e na forma propositalmente caótica de organização de seus discursos, mas, sobretudo, na potencialidade de novas percepções de mundo a que suscitam, quase explosivamente.

\title{
Limits and critical intersections between science and society: Max Horkheimer and his interdisciplinary materialism
}

\begin{abstract}
In the scope of the journal's proposal for reflection, we offer a brief but very timely discussion about the aporias of the relationship between science and society from a key context in which it is problematized: the interdisciplinary materialism of Max Horkheimer. Thus, we try to present some of its main characteristics and limits, examining the critical possibilities of knowledge production within the capitalist production system.
\end{abstract}

Keywords: Science and society. Interdisciplinary materialism. Max Horkheimer. Critical theory. The Frankfurt School.

13 - Como complementa Bonß (1993, p. 119): "This crisis of science thus also means a crisis of its methods, and overcoming the aporias Horkheimer described correspondingly pressuposes the development of an alternative methodology. However, this issue is never raised; from a methodological point of view, Horkheimer's conception remains largely conventional". 


\section{REFERÊNCIAS}

$B O N B, W$. The program of interdisciplinary research and the biginnings of critical theory. In: BONB, W.; MCCOLE, J. (Orgs.). On Max Horkheimer: new perspectives. Baskerville: MIT, 1993. HORKHEIMER, M. Teoria tradicional e teoria crítica. In: BENJAMIN, W. et al. Textos escolhidos. São Paulo: Abril Cultural, 1973. (Os pensadores).

HORKHEIMER, M. A presente situação da filosofia social e as tarefas de um instituto de pesquisas sociais. Praga - Estudos Marxistas, n. 7, p. 121-132, 1999.

HORKHEIMER, M. Observações sobre ciência e crise. In: HORKHEIMER, M. Teoria crítica: uma documentação. São Paulo: Perspectiva, 2012.

HORKHEIMER; ADORNO, T. W. Dialética do esclarecimento. Rio de Janeiro: Zahar, 1985.

NOBRE, M. A teoria crítica. Rio de Janeiro: Zahar, 2004.

NOBRE, M. (Org.). Curso livre de teoria crítica. Campinas: Papirus, 2008 a.

NOBRE, M. Teoria crítica hoje. In: PERES, D. et al. (Orgs.). Tensões e passagens: critica e modernidade - uma homenagem a Ricardo Terra. São Paulo: Singular, $2008 b$.

POLLOCK, F. State capitalism: its possibilities and limitations. In: ARATO, A.; GEBHARDT, E. The essential Frankfurth School reader. New York: Continuum, 1982. 